\title{
INTELECTO, VONTADE E CORREÇÃO DOS SENTIDOS NA MEDITAÇÃO SEGUNDA DE RENÉ DESCARTES
}

\author{
Edgard Vinícius Cacho Zanette ${ }^{1}$ \\ Universidade Estadual de Roraima (UERR) \\ (D) https://orcid.org/0000-0002-2395-2632
}

\begin{abstract}
RESUMO:
Neste artigo abordaremos como a inspeção do espírito ocorre tratando a percepção da cera como um poder intelectual de conhecer, em vista da natureza do ego cogitans, na medida que a faculdade do entendimento e a faculdade da vontade operam por complementaridade. Para tanto, abordaremos a Meditação Segunda, sobretudo a segunda parte desta meditação (a partir do parágrafo doze), com complementos explicativos de outras meditações e obras do filósofo, de forma a mostrarmos que a questão da correção dos sentidos, diante do impasse epistêmico ocasional na apreensão dos dados sensíveis, remete implicitamente ao jogo operativo da teoria cartesiana das faculdades.
\end{abstract}

PALAVRAS-CHAVE: Descartes; Cogito; Metafísica.

\section{INTELLECT, VOLITION AND CORRECTION OF THE SENSES IN MEDITATION SECOND OF RENÉ DESCARTES}

\begin{abstract}
:
We will see on this study how the inspection of the spirit is dealing with the perception of wax as an intellectual power to know, in order the nature of the ego cogitans, as the faculty of understanding and the faculty of desire operate by complementarity. Therefore we will address the Second Meditation, especially the second part of this meditation (from the paragraph twelve), with explanatory complements from other meditations and works of the philosopher, to show the issue of correcting the way, facing the occasional epistemic impasse on the apprehension of sensitive data, implicitly refers to the operating set of Cartesian theory of faculties.
\end{abstract}

1 Doutor em Filosofia pela Universidade Estadual de Campinas (UNICAMP), São Paulo - Brasil e professor efetivo de filosofia da Universidade Estadual de Roraima (UERR), Roraima - Brasil. E-mail: edgardzanette1@gmail.com 
KEYWORDS: Descartes; Cogito; Metaphysics.

Após a descoberta do cogito no $\S 4$ da Meditação Segunda, se desencadeia uma investigação sobre a natureza desta coisa que se descobriu como puro pensamento. Descoberta de si mesmo como ego cogitans, existência pela indubitabilidade, dúvida sobre o mundo exterior, via argumento do deus enganador, estes elementos se envolvem de tal modo que o sujeito pensante é posto em uma situação de conhecimento de si mesmo. Entre o saber que sou uma coisa existente por pensar e saber o que é essa coisa que eu mesmo sou como puro pensamento, a res cogitans promove uma estratégia filosófica radical, a inspeção do espírito. Esta radicalidade decorre, pois, da exigência em nada supor verdadeiro que não seja provado como tal, visto que impera a máxima de nada supor verdadeiro que não seja indubitável.

Ao fim do $\$ 12$ da Meditação Segunda, a demonstração que sustenta a percepção da cera é tomada como poder intelectual de conhecer ou conceber (poder de inteligir) ${ }^{2}$, e esse poder se refere necessariamente à atualização da certeza do cogito. Ora, a partir da descoberta de si mesmo e a necessidade de atualização contínua dessa certeza, o exame da cera mostra que o sujeito do pensar é manifesto por uma unidade indissolúvel e originária que assume as rédeas de todos os atos representativos como percepções imanentes ao espírito. Essa é a razão pela qual "pode acontecer que aquilo que vejo não seja de fato cera; pode também dar-se que eu não tenha olhos para ver coisa alguma; mas não pode ocorrer, quando vejo ou (coisa que não mais distingo) quando penso ver, que eu, que penso, não seja alguma coisa" ${ }^{3}$. O pensar como sentir implica ou sempre se remete à unidade do espírito, em vista de sua substancialidade. Nas palavras do filósofo:

[...] a alma humana não é composta de quaisquer acidentes, mas é uma pura substância. Pois, ainda que todos os seus acidentes se modifiquem, por exemplo, que ela conceba certas coisas, que ela queira outras, que ela sinta outras etc., é, no entanto, sempre a mesma alma. (AT, IX-1, p.10; "Resumo das meditações", Obras escolhidas, 2010, p. 132 - grifo nosso).

Tendo em vista a unidade do espírito e o poder de inteligir, assim

2 “[...] não poderia mesmo conceber pela imaginação o que é essa cera e que somente meu entendimento é quem o concebe" (AT, IX-1, p. 24; Obras escolhidas, 2010, p. 148). Conforme a praxe, apresentaremos as citações das obras de Descartes da seguinte forma: Citamos o volume e as páginas correspondentes à edição standard das obras completas de Descartes francês-latim, de Charles Adam e Paul Tannery (AT), sem que mencionemos, por economia, o nome do autor. Para as demais citações, seguimos as obras que estão nas Referências Bibliográficas. As traduções do francês para o português são nossas.

3 AT, IX-1, p. 25; Obras escolhidas, 2010, p. 149. 
como considerando as faculdades dos sentidos e da imaginação, existe outra faculdade ou poder pelo qual sou o que sou? Descartes apresenta intencionalmente outra força de agir que é própria ao espírito em um modo de ser diferenciado ou intermediário. Esse outro poder (faculdade) que reside no espírito é a capacidade de julgar. Entre o conceber e o julgar há uma relação de proximidade, de complementaridade, e mesmo de intimidade. Espírito ou alma, a res cogitans é uma coisa pensante que está lançada no ser e no tempo, pois ela está posta no ser e no tempo. Ora, essa temporalidade pela qual o ego cogitans, o eu pensante, habita como ser que pensa e que sente, ela remete a absorção de pensamentos e representações, e esta remissão implica em apreender e agir sobre estes conteúdos percebidos.

Há uma passagem no $\S 14$ que discute um exemplo interessante. A discussão pode ser interpretada como um complemento do exemplo da cera, ou como sua contraprova. Isso porque a capacidade de julgar é apresentada por uma proximidade e complementaridade em relação à faculdade do entendimento. Vamos aqui chamar esse caso de exemplo dos espectros. Vejamos o que afirma o filósofo no $§ 14$ :

[...] pelos termos da linguagem comum; pois nós dizemos que vemos a mesma cera, se no-la apresentam, e não que julgamos que é a mesma, pelo fato de ter a mesma cor e a mesma figura: donde desejaria quase concluir que se conhece a cera pela visão dos olhos e não somente pela inspeção do espírito, se por acaso não olhasse pela janela homens que passam pela rua, à vista dos quais não deixo de dizer que vejo homens da mesma maneira que digo que vejo a cera; e, entretanto, que vejo desta janela, senão chapéus e casacos que podem cobrir espectros ou homens fictícios que se movem apenas por molas? Mas julgo que são homens verdadeiros e assim compreendo, somente pelo poder de julgar que reside em meu espírito, aquilo que acreditava ver com meus olhos. (AT, IX-1, p. 25; Obras escolhidas, 2010, p. 148 - grifo nosso).

Nessa passagem, o aspecto intuitivo do espírito é complementado pela apresentação do juízo como um poder de julgar que é passível de ser voltado sobre o que o sujeito acreditava ver sensivelmente. O julgamento é o âmbito no qual o erro e o acerto podem manifestar-se por deliberação do sujeito. Na passagem acima, a expressão final mostra que "julgo que são homens verdadeiros e assim compreendo, somente pelo poder de julgar que reside em meu espírito, aquilo que acreditava ver com meus olhos".

Essa é a razão pela qual, para conhecer qualquer coisa sensivelmente, faz-se necessário que o espírito se conheça melhor que qualquer outra coisa. A compreensão significativa e o julgamento elegedor, estes dois elementos permitem a fluidez do perceber de um ato mental, e, a partir daí, de manifestar posição diante desta percepção, que não é outra coisa que o ato de julgar. A tomada de posição diante do que é manifesto, esta capacidade do sujeito de operar mentalmente e fazer que suas representações sejam 
intencionais, de forma que possam levar à formação de uma ação mental em vista da percepção primeira, faz da interação entre o entendimento e a vontade uma das peças-chave da teoria cartesiana das faculdades. Note-se, pois, que para conseguir examinar a natureza do espírito nestas suas capacidades, a crítica ao sensualismo leva a alma a tomar consciência de que o pensar em geral, seja quais fores as particularidades sobre as quais ele se aplique, carrega consigo a atualização do pensamento em sua caracterização como força conhecedora. Diante dessa capacidade, o julgamento emerge como possibilidade de deliberação significativa, de modo que a transparência do que conheço, no caso da cera ou ao ver homens pela janela, não está nos objetos vistos, mas na posse do conhecimento que tenho de mim mesmo. Conforme afirma o filósofo: "e encontram-se ainda tantas coisas no próprio espírito que podem contribuir ao esclarecimento de sua natureza, que aquelas que dependem do corpo (como esta - da cera) não merecem quase ser enumeradas"4.

A percepção intelectual da cera e dos homens que passam na rua não está condicionada ao puro sensualismo. Descartes pensa as coisas materiais, para o sujeito pensante, em vista a capacidade de a alma compreender o sensível. Nota-se que ele pretende superar certa dificuldade de um modo que seria "vulgar" de tratar as coisas sensíveis, e esta "vulgaridade" está posta, pois os prejuízos da vida pré-filosófica do sujeito pensante sempre estão presentes. Não é o caso de o sujeito pensante ter percebido a coisa sensível, primeiramente, e depois, a partir daí, elevar pela percepção intelectual o objeto sensível ao nível de um objeto inteligível. Ora, não há um conhecimento da cera que é transformado em conhecimento puro ou intelectual, como que rompendo com o que teria sido percebido primeiramente como sensível. Na percepção da cera, essa mudança do objeto lança continuamente ao ego a seguinte questão: que é a percepção de uma coisa como coisa?

Nesse caso, a compreensão da cera não se remete, em primeira instância, ao testemunho dos sentidos, mas se volta para a permanência que a percepção intelectual consegue abarcar, ao ser indicada e discernida uma identidade que não se desfez. Dessa forma, nesse momento das Meditações não se coloca em questão o engano dos sentidos com qualquer intenção de defender que eles se corrigem, mas sim para mostrar que nada há de mais fácil a conhecer do que o próprio espírito. Na cera, as mudanças contínuas dos corpos ali em questão não levaram a alma a percebê-los como objetos sensíveis, por exemplo, por serem vistos ou tocados, mas sim como objetos intuídos ou inteligidos. É por isso que o filósofo afirma que:

[...] propriamente falando, só concebemos os corpos pela faculdade de entender em nós existente e não pela imaginação e pelos sentidos, e que não os conhecemos pelo fato de os ver

$4 \quad$ AT, IX-1, p. 26; Obras escolhidas, 2010, p. 150. 
ou de tocá-los, mas somente por os conceber pelo pensamento.

(AT, IX-1, p. 26; Obras escolhidas, 2010, p. 150).

A noção de a correção dos sentidos operar segundo a própria natureza, isto é, de forma totalmente independente da concepção do espírito, constitui, na verdade, a tese dos autores das "Sextas objeções". Como é evidente, nesse âmbito, caso os sentidos fossem autônomos e tivessem em si mesmos a capacidade de se autocorrigirem imediatamente em relação ao juízo verdadeiro, não haveria a intervenção de um agente externo ao sensível, de forma que o espírito não poderia ser tratado como o que há de mais fácil a ser conhecido. Em relação ao exemplo do pau na água, os objetores apresentam uma defesa do sensível e uma crítica ao entendimento. Essa problematização dos graus dos sentidos contribui para a compreensão do exame da cera, pois ela discute a tese de que nada há de mais fácil a ser conhecido do que o ego cogitans.

Em resumo, a crítica dos objetores é a seguinte: “[...] dizeis que há que desconfiar dos sentidos, e que a certeza do entendimento é muito maior que a deles. Mas como isso é possível se o mesmo entendimento não possui outra certeza que a que toma dos sentidos bem dispostos?". . Ao tratarem as coisas sensíveis de modo autônomo, tal que elas fossem capazes de se corrigir sem nenhuma intervenção da capacidade de inteligir do sujeito percipiente, os objetores na verdade confrontam Descartes com um dos maiores prejuízos "realistas". Cabe mostrar que este radical "eu sinto", pelo qual os sentidos se corrigem, é incapaz de conceber a verdade da coisa percebida sem a intervenção unificadora e significativa do ego. Assim, para o filósofo, faz-se necessário que esse realismo, de certo modo "ingênuo", ceda ao estudo aprofundado do ego cogitans, o qual é tanto quem acessa a cera intelectualmente quanto o agente capaz de resolver a questão do pedaço de pau na água.

Mas essa superação do "sujeito dos sentidos" é mesmo possível? Com outras palavras, é o caso de refutar a verdade do sensível? Somos reconduzidos a considerar que essa superação é mais uma ordenação que uma descaracterização da verdade dos sentidos. Isso posto, rebatendo a crítica ao entendimento em detrimento daquela radical defesa do sensível ${ }^{6}$, o filósofo defende que os mecanismos causais dos sentidos, em relação ao sujeito pensante, não são todos opacos, de modo que fosse necessário explicitar em que consiste a certeza dos sentidos a partir de uma divisão em três graus.

O primeiro grau dos sentidos refere-se apenas ao "efeito que causam imediatamente no órgão corporal os objetos exteriores, e este não pode ser mais que o movimento das partículas do órgão, e a mudança de figura e

5 AT, VII, p. 418; Obras filosóficas, 1945, p. 338-339.

$6 \quad$ AT, IX-1, p. 236; "Sextas respostas", Ponto 9. 
situação que de dito movimento provém"7 . Aqui se trata, literalmente, das operações estritamente mecânicas entre objetos sensíveis e órgãos externos do corpo humano.

Já o segundo grau dos sentidos:

[...] contém tudo o que imediatamente resulta no espírito de sua união com o órgão corporal movido e disposto assim pelos objetos; por exemplo, os sentimentos de dor, prazer, fome, sede, das cores, dos sons, sabores e odores, do quente e do frio, e outros semelhantes, que provêm, segundo dizemos na Sexta Meditação, da união, e por assim dizer, da mescla do espírito com o corpo. (AT, IX-1, p. 236; Obras filosóficas, 1945, p. $352)$.

O terceiro grau dos sentidos, diferentemente dos outros dois, pois o primeiro é estritamente mecânico e o segundo psicofísico, é estritamente intelectual, e "compreende todos os juízos que são usualmente formamos desde nossa juventude acerca das coisas que há ao redor de nós, por ocasião das impressões ou movimentos que se produzem nos nossos órgãos de sentidos" ". O terceiro grau dos sentidos consiste, pois, estritamente na ação imanente ao próprio entendimento, que seria capaz de ultrapassar a simples impressão sensível, mostrando que, pelas impressões recebidas, a alma é capaz de discernir sobre sua existência, sua situação e mesmo sobre as propriedades do objeto. Ademais, conforme diz o filósofo:

[esta] certeza do entendimento é maior do que a dos sentidos, nossas palavras significam unicamente que os juízos que formamos em idade mais avançada, a causa de algumas observações novas que temos feito, são mais certas que as que temos formado desde a infância sem havê-los refletido; no qual não pode caber dúvida alguma, pois é sabido que não se trata aqui do primeiro nem do segundo grau do sentimento, porque neles não pode haver nenhuma falsidade. (AT, IX-1, p. 238; Obras filosóficas, 1945, p. 353 - interpolação nossa).

É por isso que a ação de julgar da alma não se remete aos dados sensíveis "brutos", isto é, tal qual são percebidos ou dados sem a intervenção do discernimento do espírito, pois, dessa forma, não há como atribuir qualquer espécie de falsidade. Sendo assim, ela se refere à ação perceptiva que "lança luz" sobre o problema em tela, a qual, sendo a única capaz de corrigir o erro dos sentidos, é sinonimo de discernimento e de presença de uma determinada concepção intelectual. Decorre daí a afirmação do filósofo: "[...] só o entendimento corrige o erro do sentido, sendo impossível alegar jamais exemplo algum em que o erro proceda de haver-se fiado mais na operação do espírito do que na percepção dos

7 AT, IX-1, p. 236; Obras filosóficas, 1945, p. 352.

$8 \quad$ AT, IX-1, p. 236; Obras Filosóficas, 1945, p. 352. 
sentidos"9.

Note-se que, ao apresentar os três graus dos sentidos e discutir acerca do problema do pedaço de pau na água, Descartes leva em conta a tese defendida pelos objetores. Para eles, os sentidos são capazes de se corrigir, visto que, se a visão percebia equivocadamente o objeto como torto, o tato seria capaz de mostrar que o objeto é reto. Por sua vez, Descartes não discorda do auxílio do tato no exame do objeto em questão, mas ele colocaria uma expressão desconsiderada pelos objetores. Ele diria que "talvez o objeto seja reto", de forma que para saber a verdade dessa percepção fosse imprescindível ter como instância primeira o sujeito que apreende significativamente estes dados. Isso porque, quando se confrontam a impressão de um dado sensível em um órgão corpóreo com a impressão de outro dado sensível em outro órgão corpóreo, ambas sendo antagônicas, não há como decidir a partir daí entre a verdade e a falsidade. Descartes resume admiravelmente essa situação nas "Sextas respostas":

[...] ainda que [o tato] nos faça pensar que o pau está reto - e isto por esta maneira de julgar a que estamos acostumados desde a infância, e que por conseguinte pode chamar-se sentimento -, isto não basta, todavia, para corrigir o erro da vista, sendo necessário, ademais, que tenhamos alguma razão que nos mostre que nesta ocasião devemos fiar-nos melhor no juízo que formamos depois do tato, que daquele a que parece inclinar-nos o sentido da vista. (AT, IX-1, p. 238; Obras filosóficas, 1945, p. 353 - interpolação nossa).

A passagem acima mostra que há um elemento intermediário e exterior aos sentidos que é capaz de decidir entre a aceitação de um dado sensível (o da visão) em relação a outro dado sensível que lhe faz oposição (o do tato). Não ocorrendo nenhuma espécie de falsidade no primeiro e segundo graus dos sentidos, o exemplo acima é uma prova que mostra claramente haver como que uma "equipolência" entre os dois âmbitos de dados sensíveis dispostos, tal que a situação permanecesse irresolúvel sem a aplicação do terceiro elemento que opera "segundo razões". Sem a entrada em cena do poder iluminador do entendimento, não haveria como romper o equilíbrio próprio das manifestações sensíveis, visto que a ação de inteligir (intuitus mentis) é a única capaz de atribuir a validade de uma percepção (a do tato) em relação a outra (a da visão) que seria considerada insuficiente para resolver o impasse quanto ao objeto em questão (a situação do pedaço de pau na água).

Postos à prova os critérios perceptivos pelos quais julgamos a existência e a identidade de uma coisa como coisa ao raciocinar, é somente meu entendimento que permite definir a identidade do objeto a partir de sua permanência, pois ela é que apreende intuitivamente a identidade desse

$9 \quad$ AT, IX-1, p. 238; Obras Filosóficas, 1945, p. 353. 
objeto e discerne em que consiste a presença manifesta.

Em verdade, no exemplo da cera há uma espécie de prova da inconstância dos dados sensíveis, pela qual o sujeito pensante, ao acessar objetos tais como a cera, mostra-se capaz de percebê-los intelectualmente, avaliá-los, para só então, com a colaboração da faculdade da vontade, julgálos verdadeiros ou falsos. Esse também é o caso do exemplo dos espectros, no qual é o sujeito que percebe e, a partir daí, julga que são homens e não chapéus e casacos que cobririam espectros. No caso, a consciência precede o julgamento em um aspecto importante, e, por meio dele, dispõe um campo de percepções e pensamentos a serem tomados pela ação da faculdade da vontade. Se todo pensar e todo sentir supõem o sujeito, então toda atividade rememorada ou mesmo toda nova atividade perceptiva são percebidas ou dispostas pelo entendimento na atualidade do pensar.

Por sua vez, a faculdade da vontade pode manusear e escolher todo esse material infindável que é disposto pelo entendimento, pois toda ação voluntária é uma ação livre. Conforme o filósofo explica nos Princípios da filosofia, "a principal perfeição do homem é ser capaz de agir livremente e ter livre-arbítrio, e é isso o que o torna digno de louvor ou culpa"10.

A liberdade da escolha voluntária remete-se à possibilidade de romper até mesmo com a percepção atual de determinado objeto, julgando-o equivocadamente como obscuro e confuso, caso seja essa a sua intenção. Assim, toda ação voluntária, de algum modo, supõe um objeto que já foi percebido pelo intelecto, pelo menos temporalmente, enquanto, por outro lado, intencionalmente, é a faculdade da vontade que regra a própria atenção do espírito no ato de eleger, ou decidir, sobre o exercício do pensar que já foi disponível ou possível pela intervenção perceptiva da faculdade do entendimento. Por conseguinte, em certo sentido, toda eleição voluntária e livre completa ou supõe um jogo da faculdade do entendimento sempre presente, pois, se não há objeto cognoscível, sobre o que seria possível julgar? Sendo assim, no campo da consciência, há uma infinidade de objetos já experimentados e percebidos que estão disponíveis pela ação iluminadora do entendimento já exercida.

Nesse sentido, ainda que esses objetos estejam armazenados na faculdade da memória e, como bem ensina a "Quarta meditação", que a ação eletiva é totalmente livre, de um modo ou de outro, todo "e qualquer isto" ou "aquilo" disponível para ser eleito pelo exercício da vontade supõe uma história que indica a presença da intuição intelectual. Assim, não parece ser o caso de questionar o primado do entendimento como o âmbito perceptivo de apresentação do próprio representar, de forma que, por sua vez, a intervenção do ato judicativo, próprio da faculdade da vontade, emerge completando um exercício intelectual já suficientemente elaborado.

Quanto ao tema, voltemos ao caso da relação entre o entendimento e

10 AT, IX-2, p. 40; Princípios, I, XXXVII, p. 39. 
a imaginação, a partir de uma esclarecedora passagem. Diz o filósofo que, como força de inteligir, ao conceber, o espírito "volta-se de alguma forma para si mesmo e considera algumas das ideias que ele tem em si; mas, imaginando, ele se volta para o corpo e considera nele algo de conforme à ideia que formou por si mesmo ou que recebeu pelos sentidos" ${ }^{11}$. Segundo Descartes, nenhum conhecimento poderia ser alcançado sem o uso do entendimento, em sua atividade perceptiva, seja ela de objetos sensíveis ou de objetos inteligíveis. Sua atividade é, antes de tudo, perceptiva, isto é, ela possui o poder de indicar a presença de um determinado objeto (seja ele material, imaterial ou metafísico). Ademais, com o uso, a atenção - que estabelece uma ponte entre o perceber e o querer - focaliza ou centra a capacidade do ego de inteligir, isto é, de perceber intelectualmente algo na duração. Ao inspecionar determinado objeto no tempo, pois o ego, evidentemente, é um sujeito temporal, a atenção é o que orienta a capacidade de distinguir intelectualmente os objetos do representar, tornando possível o próprio ato abstrativo. $\mathrm{Na}$ "Carta a Regius", de maio de 1641, a atividade da alma é explicada como paixão, ainda que todo ato representativo implique a ação da alma. ${ }^{12}$ Nos Princípios I, LIII, o filósofo explica que há um sentido fundamental pelo qual a alma, como coisapensamento, ou coisa que pensa, é mais entendimento do que vontade. Nas palavras do filósofo:

[...] o pensamento constitui a natureza da substância pensante, pois todas as outras coisas que podem ser atribuídas ao corpo pressupõem a extensão e não passam de um modo da coisa extensa; bem como todas as propriedades que descobrimos no espírito são apenas modos diversos do pensar. Assim, por exemplo, não podemos conceber a figura senão em algo extenso, nem o movimento senão num espaço extenso, nem a imaginação, a sensação ou a vontade, senão em uma coisa pensante. (AT, IX-2, p. 48; Princípios, 2007, p. 45- 46 - grifo nosso).

O entendimento é caracterizado como finito e limitado. Isso não quer dizer que ele seja frágil ou mesmo inferior a qualquer outra faculdade. Ao contrário, na verdade sua limitação é indício de sua precisão, de sua natureza bem-disposta. Em geral, os dados que são adequadamente percebidos podem ser acessados e abarcados pela intuição intelectual. Com efeito, há uma exceção a essa regra. Ora, após as provas da existência de Deus na "Terceira meditação", é reconhecida uma ideia que se refere a uma realidade que escapa ou ultrapassa o limite perceptivo imanente ao próprio entendimento. Ao ter consciência de uma ideia que indica uma substância infinita, dita substância em sentido absoluto e independente, o ego

AT, IX-1, p.10; Obras escolhidas, 2010, p. 189.

12 AT, III, p. 372. Também nas Paixões da alma há várias passagens sobre a relação de ação e paixão entre a alma e o corpo. 
reconhece sua incapacidade em compreender (comprehendere) e aceita sua capacidade de entender (intelligere) a Deus. Isso quer dizer que o ego tem o poder de "tocá-lo pelo pensamento", mas não de abarcá-lo ou abraçá-lo em toda a sua realidade. Ao acessar a ideia de Deus, o entendimento finito, evidentemente, não esgota pelo pensar todas as perfeições desse ser. Mas, embora nosso conhecimento seja finito e não tenhamos acesso à realidade total de Deus, certamente ele é o ser mais inteligível de todos. ${ }^{13}$

Sem a percepção intelectual, não há sobre o que julgar, visto que o intelecto aparece dotado de antecedência epistêmica e temporal, podendo, em certa medida, ser caracterizado como condição de possibilidade do aparecimento do julgamento. Já a faculdade da vontade, por um lado, age conjuntamente com o entendimento, visto que a primeira possui uma virtus (força) de eleger, isto é, de escolher, que colabora de modo decisivo no exercício do pensar disposto pelo intelecto; por outro lado, a faculdade da vontade ultrapassa o entendimento em um importante aspecto, ao ser definida como infinita (indefinida). Esse é o caso porque, em sentido absoluto, apenas Deus é denominado infinito (infinito positivo), enquanto as coisas contingentes ou finitas em que não descobrirmos limites são denominadas indefinidas (infinito negativo) ${ }^{14}$ Assim, enquanto uma faculdade é caracterizada pela finitude, a outra o é pela infinitude. Descartes reconhece que é a faculdade da vontade que conduz o espírito a executar ações de forma livre e voluntária. No entanto, em toda ação é suposta uma percepção primeira pela qual a alma se dá conta de algum objeto qualquer como objeto de pensamento, seja ele qual for.

Se agisse sempre por necessidade, o homem seria um autômato intelectual, mas esse tampouco é o caso da faculdade do entendimento, pois a última também está lançada na própria historicidade da existência humana e sua ação sempre depende do movimento da atenção. A própria ação livre implica em ser mais extensa que a percepção do entendimento, o qual está limitado à contingência das circunstâncias, enquanto a vontade, por sua vez, pode ultrapassar a percepção presente e considerar a verdade ou a falsidade de determinada situação conforme lhe apraz. Há que considerar, conforme o filósofo explica nos Princípios da filosofia, que o entendimento e a vontade podem ser tomados como duas maneiras de pensar que se remetem à consciência. Vejamos o que ele quer dizer:

13 Cf. AT, IX-2, p. 37; Princípios, 2007, I, LI, p. 45. Na Entretien avec Burman (Entrevista com Burman), o filósofo explica que embora "conceber" (concevoir/concipere) e "entender" (entendrelintelligere) sejam tomados comumente como sinônimos, sobretudo na versão francesa das Meditações, quando nos referimos a Deus e suas perfeições, só podemos entendê-las, mas não compreendê-las, o que denota uma diferença, muito precisa, entre os dois termos, ainda que, em todos os outros sentidos, ao que tudo indica, o filósofo os considere como sinônimos (Cf. AT, V, p. 154).

14 Cf. AT, IX-2, p. 47; Princípios, 2007, I, XXVII, p. 36. 


\begin{abstract}
Pois todas as maneiras de pensar de que somos conscientes podem reduzir-se a duas classes gerais, uma das quais consiste na percepção ou operação do entendimento, e a outra na volição ou operação da vontade. Assim, perceber pelos sentidos (sentire), imaginar e conceber as coisas puramente inteligíveis são apenas diferentes maneiras de perceber (percipiendi); mas desejar, ter aversão, afirmar, negar e duvidar são diferentes maneiras de querer. (AT, IX-2, p. 39; Princípios, I, XXXII, p. 38).
\end{abstract}

Apesar de que, em um primeiro momento, possamos tomar essas "duas maneiras de pensar" como uma dissociação do pensar, no entanto, temos que lembrar da unidade imanente ao espírito, pela qual toda explicitação segundo camadas ou separações são abstrações que não incidiriam absolutamente na realidade da coisa, mas sim em modos distintos de explorar, compreender e significar a interioridade própria do espírito. De todo modo, não podemos fugir ao fato de que não há ação livre sem atividade representativa, enquanto é possível conceber sem querer. Sendo assim, na consciência, o ato da escolha, da eleição ou do julgamento completa ou supõe a ação perceptiva do entendimento, havendo claramente uma situação de complementaridade e não de oposição.

\title{
Referências bibliográficas
}

DESCARTES, R. Euvres. Paris: Vrin, 1996. 11 vol. Publiées par Charles Adam et Paul Tannery, 1973-8.

Discurso do método; Meditações; Objeções e respostas; As paixões da alma; Cartas. 2. ed. São Paulo: Abril Cultural, 1979. (Coleção Os Pensadores).

Obras filosóficas: objeciones e los princípios de la filosofia. Introdução: Étienne Gilson. Versão espanhola: Manuel de La Revilla. Buenos Aires: Editorial El Ateneu, 1945.

$70,1997$.

Princípios da filosofia. Tradução: João Gama. Lisboa: Edições

GUEROULT, Martial. Descartes selon l'ordre des raisons. Paris: Aubier, 1968, vol. 1.

Descartes selon l'ordre des raisons. Paris: Aubier, 1953, vol. 2.

LANDIM, Raul Ferreira Filho. A referência ao dêitico "EU" na gênese do sistema cartesiano: A res cogitans ou o homem?. In: Analytica. Rio de Janeiro, v. 1, n. 2, p. 41-67, 1994.

Evidência e verdade no sistema cartesiano. São Paulo: Loyola, 1992 (Coleção Filosofia; 23).

Idealismo ou realismo na filosofia primeira de Descartes. In:

Analytica. Rio de Janeiro, v. 2, n. 2, p. 129-159, 1997.

LEVY, L. Eu sou, eu existo: isto é certo; mas por quanto tempo? In: Analytica. Rio de Janeiro, v. 2, n. 2, p. 161-185, 1997. 
MARION, J-L. Sur l' ontologie grise de Descartes. 2. ed. PARIS: Vrin, 1991.

MOYAL, J. D. (Ed.). René Descartes critical assessments. London/New York: Routledge, 1991, 4 v.

ROCHA, Ethel Menezes. Animais, Homens e Sensações Segundo Descartes. In: KRITERION. Belo Horizonte, no 110, p. 350-364, dez./2004.

Prudência da Vontade e Erro em Descartes. In: Verdade, conhecimento e ação: ensaios em homenagem a Guido Antônio de Almeida e Raul Landim Filho. São Paulo: Edições Loyola, p. 325-337, 1999.

TEIXEIRA, Lívio. Ensaio sobre a moral de Descartes. 2. ed. São Paulo: Brasiliense, 1990. 